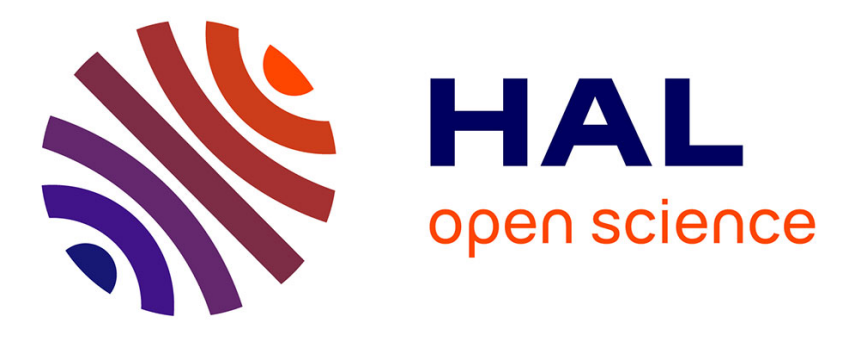

\title{
Pathogenic microorganisms carried by migratory birds passing through the territory of the island of Ustica, Sicily (Italy)
}

Maria Foti, Donatella Rinaldo, Annalisa Guercio, Cristina Giacopello, Aurora Aleo, Filomena Deleo, Vittorio Fisichella, Caterina Mammina

\section{To cite this version:}

Maria Foti, Donatella Rinaldo, Annalisa Guercio, Cristina Giacopello, Aurora Aleo, et al.. Pathogenic microorganisms carried by migratory birds passing through the territory of the island of Ustica, Sicily (Italy). Avian Pathology, 2011, 40 (04), pp.405-409. 10.1080/03079457.2011.588940 . hal-00722796

\section{HAL Id: hal-00722796 https://hal.science/hal-00722796}

Submitted on 4 Aug 2012

HAL is a multi-disciplinary open access archive for the deposit and dissemination of scientific research documents, whether they are published or not. The documents may come from teaching and research institutions in France or abroad, or from public or private research centers.
L'archive ouverte pluridisciplinaire HAL, est destinée au dépôt et à la diffusion de documents scientifiques de niveau recherche, publiés ou non, émanant des établissements d'enseignement et de recherche français ou étrangers, des laboratoires publics ou privés. 


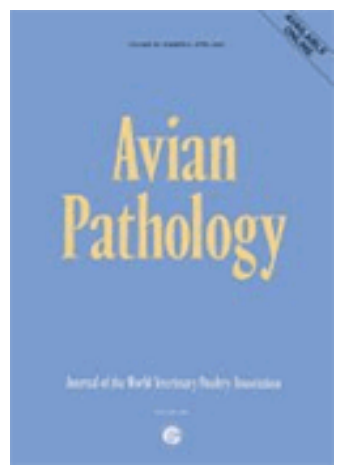

\section{Pathogenic microorganisms carried by migratory birds passing through the territory of the island of Ustica, Sicily (Italy)}

\begin{tabular}{|c|c|}
\hline Journal: & Avian Pathology \\
\hline Manuscript ID: & CAVP-2010-0183.R2 \\
\hline Manuscript Type: & Original Research Paper \\
\hline $\begin{array}{r}\text { Date Submitted by the } \\
\text { Author: }\end{array}$ & 21-Mar-2011 \\
\hline Complete List of Authors: & $\begin{array}{l}\text { Foti, Maria; University of Messina, Veterinary Public Health } \\
\text { Rinaldo, Donatella; University of Messina, Veterinary Public Health } \\
\text { Guercio, Annalisa; IZS Sicilia } \\
\text { Giacopello, Cristina; University of Messina, Veterinary Public Health } \\
\text { Aleo, Aurora; University of Palermo, Sciences for Health Promotion } \\
\text { DeLeo, Filomena; University of Messina, Veterinary Public Health } \\
\text { Fisichella, Vittorio; University of Messina, Veterinary Public Health } \\
\text { Mammina, Caterina; UNiversity of Palermo, Sciences for Health } \\
\text { Promotion }\end{array}$ \\
\hline Keywords: & migratory birds, zoonotic agents, Sicily, antibiotic resistance \\
\hline
\end{tabular}

\section{SCHOLARONE}

Manuscripts 
Comparative in vivo safety and efficacy of a glycoprotein G-deficient candidate vaccine strain of infectious laryngotracheitis virus delivered via eye-drop

Mauricio J. C. Coppo ${ }^{1}$, Amir H. Noormohammadi ${ }^{1}$, Carol A. Hartley ${ }^{2}$, James R. Gilkerson $^{2}$, Glenn F. Browning ${ }^{2}$ and Joanne M. Devlin ${ }^{2,3} *$

Short Title: Comparative study of $\Delta \mathrm{gG}$-ILTV delivered by eye-drop

${ }^{1}$ Asia-Pacific Centre for Animal Health, Faculty of Veterinary Science, The University of Melbourne, Werribee, Victoria, 3030, Australia ${ }^{2}$ Asia-Pacific Centre for Animal Health, Faculty of Veterinary Science, The University of Melbourne, Parkville, Victoria, 3010, Australia ${ }^{3}$ The Australian Poultry CRC

* Joanne M. Devlin, Faculty of Veterinary Science, The University of Melbourne, Parkville, Victoria, 3010 Australia. Ph: +61 90358110, Fax: +61 3 83447374, Email: devlinj@unimelb.edu.au

Received: 14 March 2011 


\section{Abstract}

Infectious laryngotracheitis (ILT) is an acute respiratory disease in poultry that is commonly controlled by vaccination with conventionally attenuated virus strains.

Despite the use of these vaccines, ILT remains a threat to the intensive poultry industry. Our laboratory has developed a novel candidate vaccine strain of infectious laryngotracheitis virus (ILTV) lacking glycoprotein $\mathrm{G}(\Delta \mathrm{gG}-\mathrm{ILTV})$. The aim of this study was to directly compare this candidate vaccine with three currently available commercial vaccines in vivo. Five groups of specific-pathogen-free chickens were eyedrop inoculated with one of the three commercial vaccine strains (SA2-, A20- or ServaILTV), or $\Delta \mathrm{gG}-\mathrm{ILTV}$, or sterile media. Vaccine safety was assessed by examining clinical signs, weight gain and persistence of virus in the trachea. Vaccine efficacy was assessed by scoring clinical signs and conducting post-mortem analyses following challenge with virulent virus. Following vaccination, birds that received $\Delta \mathrm{gG}$-ILTV had the highest weight gain among the vaccinated groups and had clinical scores that were significantly lower than birds vaccinated with SA2- or A20-ILTV, but not significantly different from those of birds vaccinated with Serva-ILTV. Analysis of clinical scores, weight gain, tracheal pathology and virus replication after challenge revealed a comparable level of efficacy for all vaccines. Findings from this study further demonstrate the suitability of $\Delta \mathrm{gG}-\mathrm{ILTV}$ as a vaccine to control ILT. 


\section{Introduction}

Infectious laryngotracheitis virus (ILTV) is an alphaherpesvirus that causes severe and economically significant respiratory disease in poultry worldwide (Guy \& García, 2008). Shortly after infectious laryngotracheitis (ILT) was first described by May and Tittsler (May \& Titsler, 1925), immunisation of chickens was achieved by inoculating virulent virus into the cloaca (Brandly \& Bushnell, 1934), the first effective vaccine developed for a major avian viral disease (Guy \& García, 2008). Subsequently, attenuated live ILTV vaccines were developed by consecutive passage of virulent virus in cell culture and/or embryonated chicken eggs. Attenuated live ILTV vaccines are now commonly used in commercial poultry flocks worldwide (Guy \& García, 2008).

Attenuated live ILTV vaccines have been associated with several adverse effects, including transmission of virus to unvaccinated birds (Ojkic et al., 2006; Oldoni \& García, 2007; Neff et al., 2008; Oldoni et al., 2008), insufficient attenuation (Guy et al., 1990; Kirkpatrick et al., 2006; Oldoni et al., 2009), establishment of latency (Bagust, 1986; Williams et al., 1992), subsequent reactivation of infection (Hughes et al., 1989; Hughes et al., 1991; Bagust \& Johnson, 1995) and increased virulence after bird-to-bird passage (Guy et al., 1991). Furthermore, once a flock has been vaccinated with an attenuated ILTV strain, it is difficult to subsequently determine whether birds have been infected with vaccine or virulent field strains. This is an important consideration in disease eradication programs (Bagust \& Johnson, 1995).

In recent years, recombinant viruses that express immunogenic antigens from ILTV have been generated. Many of these recombinant vaccines are able to induce protective immunity without the problems associated with the re-emergence of latent virus in carrier individuals (Davison et al., 2006; Mebatsion et al., 2008; Sun et al., 2008). 
Recombinant ILTV strains that lack specific virulence factors have also been developed. These ILTV strains have the potential to be used as vaccines that avoid many of the problems associated with conventionally attenuated vaccines (Devlin et al., 2006; Helferich et al., 2007; Mundt et al., 2010; Pavlova et al., 2010).

A glycoprotein $\mathrm{G}(\mathrm{gG})$ deletion mutant of ILTV ( $\triangle \mathrm{gG}$-ILTV) has previously been developed in our laboratories (Devlin et al., 2006). A number of studies have been carried out to assess the suitability of this recombinant virus as a vaccine candidate. These studies have demonstrated a number of desirable characteristics including attenuation, immunogenicity and suitability for large-scale administration through eyedrop or drinking-water (Devlin et al., 2007; Devlin et al., 2008). The lack of a specific anti-gG humoral response to this recombinant virus may allow the development of serological tests to discriminate between vaccinated and naturally infected individuals (Devlin et al., 2007). Although these preliminary studies have indicated that $\Delta \mathrm{gG}-\mathrm{ILTV}$ appears to be suitable for use as an ILTV vaccine, the safety and efficacy of this vaccine candidate has not been directly compared with commercial ILTV vaccines following administration via a commercially viable route.

The aim of this study was to directly compare the in vivo safety and efficacy of $\triangle \mathrm{gG}-\mathrm{ILTV}$ with three commercially available conventionally attenuated ILTV vaccines following eye-drop inoculation.

\section{Materials and Methods}

Virus strains and propagation. The $\Delta \mathrm{gG}$-ILTV strain was generated from the virulent CSW-1 ILTV strain (Devlin et al., 2006). The commercial vaccine strains SA2-ILTV 
and A20-ILTV were obtained from Fort Dodge Australia Pty Ltd, Baulkham Hills. The attenuated SA2-ILTV strain was derived from a virulent field isolate of ILTV by sequential passage in embryonated chicken eggs (Purcel \& Surman, 1974). The attenuated A20-ILTV originated from 20 passages of SA2-ILTV clone A in primary cell culture followed by 5 passages in embryonated eggs to lessen residual virulence (Bagust \& McGavin, 1991). Serva-ILTV is a recently introduced vaccine strain to Australia (Intervet Australia Pty Ltd, Bendigo). All these commercial vaccine strains are prepared in embryonated chicken eggs.

Experimental design. The animal experiment described in this study had approval from the Animal Ethics Committee of the Faculty of Veterinary Science, The University of Melbourne (Animal Ethics ID: 0911261.1). One hundred and one specific-pathogenfree (SPF) hybrid white leghorn chickens (SPAFAS Australia Pty Ltd, Woodend), at 3 weeks of age were randomly allocated to one of five experimental groups. Each group contained 20 or 21 birds and each group was housed in a separate isolator unit and received feed and water ad libitum. Each bird was individually identified using a numbered wing-tag. On the first day of the experiment each bird was weighed. Birds were then vaccinated via eye-drop with one of the three commercial vaccine strains according to manufacturers' specifications using label doses, or were vaccinated with $\Delta \mathrm{gG}-\mathrm{ILTV}$, or were inoculated with sterile media. Viral titres of each commercial vaccine dose, as informed by manufacturers were $\geq 10^{4.10}$ plaque forming units (PFU) for SA2-ILTV $10^{3.70}$ PFU for A20-ILTV and $\geq 10^{2.50}$ median tissue culture infective dose for Serva-ILTV. Birds that received $\triangle \mathrm{gG}$-ILTV were inoculated with $10^{3.48} \mathrm{PFU}$ suspended in $30 \mu \mathrm{l}$ sterile media, as previously described (Devlin et al., 2008). 
Twenty-one days after vaccination, all birds were weighed and serum was collected from each bird. Tracheal swabs were also collected from each of the vaccinated birds and immediately placed in $500 \mu \mathrm{l}$ of sterile media. These swab samples were stored at $80^{\circ} \mathrm{C}$ until processing. Each bird was then intra-tracheally challenged with $10^{3.65} \mathrm{PFU}$ of a virulent CSW-1 laboratory strain of ILTV. Six days after challenge, all birds were killed by exposure to halothane. Each bird was weighed and necropsied. The trachea was aseptically removed from each bird and transverse sections of the upper and lower trachea were collected for histopathological examination. The mucosa from middle tracheal segments was scraped using sterile scalpel blades, transferred to $500 \mu \mathrm{l}$ of sterile media and stored at $-80^{\circ} \mathrm{C}$ until processed.

Safety. Vaccine safety was assessed by examining birds for clinical signs of disease and determining weight gain following vaccination. The persistence of virus in the trachea following vaccination was also assessed.

Five days after vaccination, all birds were individually video-recorded for a period of 30 seconds using a handheld digital video camera. Video footage was then reviewed to assess the severity of the clinical signs. General demeanour was scored on a scale of 0 - 2. Birds with a normal demeanour were scored as 0 , birds with a depressed demeanour were scored as 1 and birds with a severely depressed demeanour were scored as 2. Dyspnoea was scored on a scale of 0 - 4. Birds that showed no dyspnoea were scored as 0 , birds with mild dyspnoea (beak remaining closed) were scored as 1 , birds with moderate dyspnoea (open beak breathing) were scored 2, birds showing gasping were scored as 3, and birds showing severe gasping or that died suddenly during the experiment were scored as 4 . Signs of conjunctivitis were scored on a scale of 0 - 2. Birds with no signs of conjunctivitis were scored 0 , birds showing partial 
closure of the eyes were scored 1, and birds displaying complete closure of the eyes were scored 2. All birds showing severe respiratory distress were euthanised by exposure to halothane. Clinical scores were summed to give an overall clinical score.

The weight gain of each bird, 21 days after vaccination, was recorded and used to calculate the percentage weight gain for each bird following vaccination. The mean percentage weight gain for male and female birds in each experimental group was then calculated.

Tracheal swabs collected from vaccinated birds and blood samples collected from all birds 21 days after vaccination were examined for the presence of ILTV DNA and antibody against ILTV, respectively (see below).

Efficacy. Vaccine efficacy was measured by assessing clinical signs and weight gain after challenge. Tracheal pathology and viral replication in the trachea after challenge were also examined as a measure of vaccine efficacy.

Clinical signs were scored 5 days after challenge as described above. The weight of each bird was recorded 6 days after challenge (following euthanasia) and used to calculate the percentage weight gain of each bird over the 5 day period following challenge. Weight gain was then compared between experimental groups.

Tracheal histopathology was assessed by examination of sections of the upper and lower tracheal collected during necropsy. Sections were collected into Bouin's fixative, embedded in paraffin, stained with haematoxylin and eosin, and then examined using light microscopy. The severity of histopathological lesions was scored using a previously described system (Guy et al., 1990).

Mucosal scrapings of the mid-trachea collected from each vaccinated bird at necropsy were assessed for the presence of ILTV DNA (see below). 
Analysis of viral persistence and replication in tracheal tissue. Tracheal swabs (collected after vaccination) and tracheal mucosal scrapings (collected at necropsy) were examined for the presence of ILTV DNA using quantitative PCR (qPCR). Samples were prepared for DNA extraction using VX Universal Liquid Sample DNA Extraction Kit (Qiagen) and a Corbett X-tractor Gene Robot (Corbett Australia). Following DNA extraction, qPCR was performed using primers that amplify a $116 \mathrm{bp}$ section of the UL15 gene of ILTV. This qPCR was performed essentially as previously described (Devlin et al., 2006; Kirkpatrick et al., 2006) with some minor modifications. Briefly, the $20 \mu \mathrm{l}$ reaction contained $50 \mu \mathrm{M}$ of each $\mathrm{dNTP}, 1 \mathrm{mM} \mathrm{MgCl}_{2}, 8 \mu \mathrm{M}$ Syto9 (Invitrogen), $0.125 \mu \mathrm{M}$ of each primer (UL15f: 5' - TTGCTGTGCTATTTCGCGTG - 3'; UL15r: 5' - GTAAATCGTTTAGTGCGGCAT - 3'), 4 l 5x Green GoTaq® Flexi Buffer (Promega, Madison WI) and 1.25 U GoTaq ${ }^{\circledR}$ DNA Polymerase (Promega). The template was $2 \mu \mathrm{l}$ of extracted DNA or 10 -fold serial dilutions, in triplicate, of a sample containing $4.11 \times 10^{8}$ copies of the $116 \mathrm{bp}$ UL15 sequence in pGEM-T (Promega) to generate a standard curve. Each reaction was incubated in a Rotorgene 6000 thermocycler (Corbett Life Science, NSW Australia) at $94^{\circ} \mathrm{C}$ for 2 minutes, followed by 40 cycles of denaturation at $94^{\circ} \mathrm{C}$ for 20 seconds, annealing at $59^{\circ} \mathrm{C}$ for 20 seconds and extension at $72^{\circ} \mathrm{C}$ for 10 seconds, with a final extension step at $72^{\circ} \mathrm{C}$ for 5 minutes. Products were then subjected to temperature increments of $0.2^{\circ} \mathrm{C}$ from $78^{\circ} \mathrm{C}$ to $85^{\circ} \mathrm{C}$ to examine the melting pattern of the amplicons. All samples containing more than 20 copies per reaction (1.30 $\log _{10}$ viral copies) were regarded as positive.

Analysis of antibody against ILTV. Serum samples were examined for the presence and concentration of antibodies against ILTV using the Trop-ELISA ILT kit (TropBIO 
Pty. Ltd., Australia) according to the manufacturer's instructions. All positive samples with optical density values above the highest observed value of the standard curve of the test $(2.30 \pm 0.32)$ were considered to have titres of 1300 relative units for statistical purposes. All samples with a titre lower than 5 relative units were considered negative.

Statistical analysis. Minitab 15 (Minitab Pty Ltd, NSW, Australia) and Microsoft® Office Excel 2003 were used to analyse all data. The weight gains of male and female birds were analysed separately as there were different numbers of female and male birds in each experimental group. Student's t-test was used to compare the weight gains between the groups. Clinical scores and tracheal pathology scores were compared between groups using Mann-Whitney tests. Virus copy numbers from qPCR results were transformed to a $\log _{10}$ base and analysed using Student's t-test. The proportions of birds that were ELISA positive or qPCR positive for the presence of ILTV DNA, after vaccination or challenge, were calculated and assessed using Fisher's exact test.

Differences in ELISA titres between groups were tested for significance by analysis of variance. $P$ values $\leq 0.05$ were considered significant.

\section{Results}

Vaccine safety. The weight gains of male and female birds in each group after vaccination are summarised in Figure 1. Male and female birds inoculated with the novel vaccine candidate $\Delta \mathrm{gG}$-ILTV had mean percentage weight gains of $158.9 \%$ and $138.4 \%$, respectively. These gains were not significantly different from those of 
unvaccinated birds. Female birds inoculated with Serva-ILTV had weight gains that were not significantly different from those of unvaccinated female birds. Male birds that were inoculated with either SA2-ILTV or Serva-ILTV had weight gains that were not significantly different from those of the $\Delta \mathrm{gG}$-ILTV group but were significantly $(P \leq$ 0.04) lower than those of unvaccinated birds. Male and female birds inoculated with A20-ILTV had the lowest mean percentage weight gains (118.8\% and 109.6\%, respectively), and these were significantly $(P<0.01)$ lower than those of all other vaccinated groups and the unvaccinated group.

Clinical sign scores and qPCR results 5 and 21 days after vaccination, respectively, are summarised in Table 1. Birds vaccinated with Serva-ILTV had the lowest median overall clinical score, but this was was not significantly different from that of unvaccinated birds. Birds vaccinated with $\triangle \mathrm{gG}$-ILTV had a median overall clinical score that were not significantly different from that of birds vaccinated with ServaILTV. The overall clinical score of birds vaccinated with $\Delta \mathrm{gG}-\mathrm{ILTV}$ was significantly lower than those of birds vaccinated with SA2-ILTV or A20-ILTV $(P<0.01$ and $P=$ 0.02, respectively). Birds vaccinated with SA2-ILTV had the highest median overall clinical score, and this was significantly $(P<0.01)$ higher than those of all other vaccinated groups. This was mainly due to high dyspnoea scores. One bird vaccinated with SA2-ILTV died after vaccination, but the cause of death could not be definitively determined as samples could not be recovered for examination.

The group of birds vaccinated with $\triangle \mathrm{gG}$-ILTV had the lowest proportion of qPCR positive birds 21 days after vaccination, and this was significantly $(P<0.01)$ different from those of all other vaccinated groups. The SA2-ILTV group had the highest proportion of qPCR positive birds and also the highest mean number of viral copies in the trachea $\left(2.95 \log _{10} \pm 0.96\right.$ virus copy numbers $)$. 
The presence and concentration of antibodies against ILTV were assessed 21 days after vaccination using a commercial ELISA kit (Table 1). The $\triangle \mathrm{gG}$-ILTV group had a significantly $(\mathrm{P}<0.05)$ lower proportion of serologically positive birds than the other vaccinated groups, but the proportion of positive birds in this group was still significantly $(P<0.01)$ different from that of the unvaccinated group, which contained no positive birds. The SA2-ILTV group had the highest geometric mean antibody titre (624 relative units). The $\Delta \mathrm{gG}$-ILTV group had the lowest geometric mean antibody titre (35 relative units). The geometric mean antibody titres in these two groups were significantly $(P<0.01)$ different from those of all other groups.

Vaccine efficacy. Vaccine efficacy was assessed after challenge with virulent ILTV. Following challenge, one bird in the unvaccinated group died soon after showing clinical signs of ILT. Results from this bird were excluded in all analyses.

The weight gains of the birds after challenge are summarised in Figure 2. Male and female birds inoculated with the A20-ILTV had the highest mean percentage weight gains (27.5\% and $22.5 \%$ respectively) and these were significantly $(P \leq 0.05)$ higher than the weight gains of all other groups. There were no significant differences detected in the weight gains of birds (male and female) inoculated with any of the other vaccines (SA2-ILTV, Serva-ILTV or $\Delta \mathrm{gG}-\mathrm{ILTV}$ ). Weight gains of unvaccinated male birds after challenge were low $(6.9 \% \pm 6.7)$ but not significantly different from those of other groups, except for the group vaccinated with A20-ILTV $(P<0.01)$. The weight gain of unvaccinated female birds after challenge $(3.9 \% \pm 5.7)$ was also low and was significantly $(P \leq 0.02)$ different from those of SA2-ILTV and A20-ILTV, but not from those of birds vaccinated with Serva-ILTV or $\Delta \mathrm{gG}-\mathrm{ILTV}$. 
Clinical scores 5 days after challenge, and tracheal histopathology scores and qPCR results 6 days after challenge, are presented in Table 2. In all of the vaccinated groups, tracheal histopathology scores were significantly lower than those of unvaccinatedchallenged birds $(P<0.01)$. More severe histopathological lesions were observed in the upper trachea, with lesions significantly $(P<0.01)$ higher than those in lower trachea in each group, including unvaccinated-challenged birds. No significant differences in tracheal histopathology scores were detected between birds that had received an ILTV vaccine.

Six days after challenge, ILTV DNA was detected by qPCR in a significantly $(P<$ 0.01 ) higher proportion of unvaccinated birds, compared with birds in any of the vaccinated groups. There was no significant difference between the proportion of positive birds or the mean number of viral genome copies in any of the vaccinated groups (Table 2). The correlation between upper tracheal histopathology scores and tracheal viral genome copy numbers was poor $(R=0.45)$.

\section{Discussion}

This study investigated the comparative safety and efficacy of the $\Delta \mathrm{gG}$-ILTV candidate vaccine and commercial ILTV vaccine strains following eye-drop inoculation. Vaccine safety was measured by assessing clinical scores, viral persistence and weight gain. The level of safety of $\Delta \mathrm{gG}-\mathrm{ILTV}$ was considerably higher than that of SA2-ILTV and A20ILTV, but similar to that of Serva-ILTV, although Serva-ILTV was detected in tracheal specimens of a significantly higher proportion of chickens 21 days after vaccination. Vaccine efficacy was measured by assessing clinical signs, weight gain, viral replication 
and tracheal pathology after challenge. A significantly higher weight gain after challenge was observed in birds vaccinated with A20-ILTV, however, this should be considered together with the significantly lower weight gain in this group of birds before challenge.

Previous studies have assessed viral replication of $\Delta \mathrm{gG}$-ILTV in tracheal mucosa during the early stages of infection. Four days after inoculation genome copy numbers were not significantly different between $\Delta \mathrm{gG}$-ILTV and the parent wild type ILTV (Devlin et al., 2006), or between $\Delta \mathrm{gG}$-ILTV and SA2-ILTV or A20-ILTV (Devlin et $a l ., 2007)$, suggesting that the lack of gG does not impair the ability of ILTV to replicate in tracheal tissue. This current study assessed virus levels 21 days after vaccination. Compared to $\Delta \mathrm{gG}$-ILTV, the commercial vaccine strains persisted longer. This suggests that birds vaccinated with the commercial ILTV strains may be more likely to spread ILTV to naïve individuals, and that this may continue for at least 3 weeks after vaccination. This had not been evident in previous studies, thus emphasising the importance of longer term studies when assessing ILT vaccine safety.

Results from the current study have shown birds vaccinated with $\Delta \mathrm{gG}-\mathrm{ILTV}$ are efficiently protected while having comparatively lower levels of serum antibody and lower levels of viral persistence in tracheal tissue at 21 days post-vaccination. This is consistent with a protective cell-mediated rather than humoral immune responses in ILT (Fahey et al., 1983; Fahey et al., 1984; Andreasen et al., 1989; Fahey \& York, 1990; Honda et al., 1994). The biological activity described for gG in ILTV is that of a viral chemokine binding protein associated with the modulation of the host immune response (Devlin et al., 2010). Previous studies have shown that the lack of gG in ILTV results in significant attenuation of viral pathogenicity and may direct the host away from an antibody-mediated immune response and towards a cell-mediated immune response 
(Devlin et al., 2006; Devlin et al., 2010). It is possible that the lack of gG in $\Delta \mathrm{gG}-\mathrm{ILTV}$ could result in induction of a more effective immune response, with the additional advantage of comparably lower levels of pathogenicity.

An earlier study that examined the pathogenicty of ILTV strains did not find significant differences in clinical signs between birds infected with SA2-ILTV or A20ILTV 4 days after intra-tracheal inoculation (Kirkpatrick et al., 2006). However, in this current study, SA2-ILTV induced more severe clinical signs than A20-ILTV 5 days after eye-drop inoculation. Furthermore, SA2-ILTV could be detected in the trachea of a higher proportion of birds, and at a higher titre, than A20-ILTV 21 days after vaccination. This higher level of pathogenicity of SA2-ILTV is consistent with recommendations from field veterinarians that SA2-ILTV should be used only in older birds due to higher levels of residual pathogenicity (PC Scott, personal communication). Surprisingly, A20-ILTV induced significantly lower weight gains than the other ILTV vaccines. The differing results between this and previous studies are likely to be due to the different routes of administration, the different doses of virus used to inoculate the birds and the different time points that were studied.

The Serva-ILTV vaccine strain had not previously been compared to other commercial vaccine strains available in Australia, or to the $\triangle \mathrm{gG}$-ILTV candidate vaccine. This study showed that Serva-ILTV was safe and efficacious under these experimental conditions. The recent emergence of new classes of ILTV in Australia (classes 8 and 9 of ILTV according to PCR coupled restriction fragment length polymorphism analysis) phylogenetically and epidemiologically associated with the newly introduced Serva-ILTV vaccine strain, has led researchers to speculate that a subpopulation of virus could exist in this vaccine (Blacker et al., 2011). Previous studies have demonstrated sub-populations within other ILT vaccine preparations (Garcia \& 
Riblet, 2001). The existence of a sub-population within a vaccine preparation may affect the safety of the Serva-ILTV vaccine under field conditions. Further studies to investigate this hypothesis are required to fully assess the longer term safety of this vaccine.

All vaccine strains tested in this study, including the novel vaccine candidate $\Delta \mathrm{gG}-$ ILTV, induced comparable levels of protective immunity against challenge, as assessed by body weight changes, clinical scores, tracheal pathology and number of viral genome copies in the tracheal mucosa. Tracheal pathology and the number of viral copies in tracheal mucosa were the most useful parameters to assess vaccine efficacy. Only a small number of birds from each vaccinated group had simultaneous microscopic tracheal lesions and positive qPCR results. This limited the ability to fully examine the correlation between these two parameters. The tracheal histopathology score system used in this study assesses pathology caused by viral replication (eg sloughing of epithelial cells, haemorrhages) as well as the immune response to infection (eg inflammatory cell infiltraton in lamina propria) (Guy et al., 1990). In this study, upper tracheal histopathology lesions were observed in 26/61 vaccinated birds.

Histopathology scores were low $(\leq 2)$ in 23 of these birds. Low scores are generally consistent with an inflammatory response rather than acute viral replication in the mucosa. It is possible that sufficiently protected birds were capable of generating an effective immune response, resulting in histopathology scores, clearing ILTV from tracheal mucosa and resulting in lower viral genome copy number. A previous report found a positive and high correlation between these two parameters, but this was assessing pathogenicity of ILTV after primary infection not protection after challenge (Kirkpatrick et al., 2006). Clinical scores in the unvaccinated-challenged birds were not significantly different from those of vaccinated birds 5 days after challenge. This is 
consistent with previous studies examining clinical scores at this time point (Devlin et $a l ., 2008)$. Overall percentage weight gain was comparatively low in this study compared with a previous study that also examined the immunogenicity of $\Delta \mathrm{gG}$-ILTV (Devlin et al., 2008). In the current study the mean weight of the three week-old birds at vaccination was significantly higher than previous studies (data not shown). These higher initial weights are likely to be responsible for the lower percentage weight gains seen in this study, and may have subsequently affected the detection of differences in weight gains between groups. External factors, including conditions at hatching and during rearing, are likely to be responsible for the different initial weights of three week-old birds in the different studies. Weight gain has previously been used to measure the pathogenicity of ILTV and to assess protection against challenge (Kirkpatrick et al., 2006; Rodriguez-Avila et al., 2008; Rodriguez \& Garcia, 2008; Oldoni et al., 2009). A recent study, however, found that viral load and clinical signs after challenge to be more reliable measures of protection than body weight gain (Johnson et al., 2010). These findings and differences between studies highlight the importance of including multiple parameters to comprehensively assess ILTV pathogenicity and protection.

The findings from this study provide further evidence of the suitability of $\Delta \mathrm{gG}$ ILTV for use as an attenuated vaccine. Benefits of this vaccine over conventionally attenuated vaccines include the potential to serologically differentiate vaccinated birds from infected birds (Devlin et al., 2007) and enhanced vaccine safety. It would be useful to undertake further studies to examine the affects of administering higher doses of this virus via eye-drop vaccination (a dose-response study). Future studies to further examine delivery of $\Delta \mathrm{gG}$-ILTV by other methods suitable for mass vaccination of 
poultry, including in ovo delivery and drinking-water delivery, may also be useful for enhancing control of this disease.

\section{Acknowledgements}

The authors gratefully acknowledge the excellent technical assistance of Ms. Cheryl Colson, Ms. June Daly and Ms Hayley Blacker. This research was partly conducted within the Australian Poultry CRC, established and supported under the Australian Government's Research Centres Program. Mauricio Coppo is supported by Programa de Becas Bicentenario - CONICYT, Gobierno de Chile. Joanne M Devlin is supported by a postdoctoral fellowship from the Australian Research Council.

\section{References}

Andreasen, J. R., Jr., Glisson, J. R., Goodwin, M. A., Resurreccion, R. S., Villegas, P. \& Brown, J. (1989). Studies of infectious laryngotracheitis vaccines: immunity in layers. Avian Diseases, 33, 524-530.

Bagust, T. J. (1986). Laryngotracheitis (Gallid-1) herpesvirus infection in the chicken 4. Latency establishment by wild and vaccine strains of ILT virus. Avian Pathology, $15,581-595$.

Bagust, T. J. \& Johnson, M. A. (1995). Avian infectious laryngotracheitis: virus-host interactions in relation to prospects of eradication. Avian Pathology, 24, 373-391. 
Bagust, T. J. \& McGavin, D. R. (1991). Low virulence laryngotracheitis (ILT) virus for vaccinating birds. Patent Publication No. WO/1991/002053. W. I. P. Organisation.

Blacker, H., Kirkpatrick, N., Rubite, A., O'Rourke, D. \& Noormohammadi, A. (2011). Epidemiology of recent outbreaks of infectious laryngotracheitis in poultry in Australia. Australian Veterinary Journal, 89, 89-94.

Brandly, C. A. \& Bushnell, L. D. (1934). A report of some investigations of infectious laryngotracheitis. Poultry Science, 13, 212-217.

Davison, S., Gingerich, E. N., Casavant, S. \& Eckroade, R. J. (2006). Evaluation of the efficacy of a live fowlpox-vectored infectious laryngotracheitis/avian encephalomyelitis vaccine against ILT viral challenge. Avian Diseases, 50, 50-54.

Devlin, J. M., Browning, G. F., Gilkerson, J. R., Fenton, S. P. \& Hartley, C. A. (2008). Comparison of the safety and protective efficacy of vaccination with glycoproteinG-deficient infectious laryngotracheitis virus delivered via eye-drop, drinking water or aerosol. Avian Pathology, 37, 83-88.

Devlin, J. M., Browning, G. F., Hartley, C. A. \& Gilkerson, J. R. (2007). Glycoprotein $\mathrm{G}$ deficient infectious laryngotracheitis virus is a candidate attenuated vaccine. Vaccine, 25, 3561-3566.

Devlin, J. M., Browning, G. F., Hartley, C. A., Kirkpatrick, N. C., Mahmoudian, A., Noormohammadi, A. H. \& Gilkerson, J. R. (2006). Glycoprotein G is a virulence factor in infectious laryngotracheitis virus. Journal of General Virology, 87, 28392847.

Devlin, J. M., Viejo-Borbolla, A., Browning, G. F., Noormohammadi, A. H., Gilkerson, J. R., Alcami, A. \& Hartley, C. A. (2010). Evaluation of immunological responses to a glycoprotein $\mathrm{G}$ deficient candidate vaccine strain of infectious laryngotracheitis virus. Vaccine, 28, 1325-1332. 
Fahey, K. J., Bagust, T. J. \& York, J. J. (1983). Laryngotracheitis herpesvirus infection in the chicken: the role of humoral antibody in immunity to a graded challenge infection. Avian Pathology, 12, 505-514.

Fahey, K. J. \& York, J. J. (1990). The role of mucosal antibody in immunity to infectious laryngotracheitis virus in chickens. Journal of General Virology, 71, 2401-2405.

Fahey, K. J., York, J. J. \& Bagust, T. J. (1984). Laryngotracheitis herpesvirus infection in the chicken. II. The adoptive transfer of resistance with immune spleen cells. Avian Pathology, 13, 265-275.

Garcia, M. \& Riblet, S. M. (2001). Characterization of infectious laryngotracheitis virus isolates: demonstration of viral subpopulations within vaccine preparations. Avian Diseases, 45, 558-566.

Guy, J. \& García, M. (2008). Laryngotracheitis. In Y. M. Saif, A. M. Fadly, J. R. Glisson, L. L. McDougald, L. K. Nolan and D. E. Swayne (Eds.). Diseases of Poultry 12th edn (pp.137 - 152). Ames: Blackwell Publishing.

Guy, J. S., Barnes, H. J. \& Morgan, L. M. (1990). Virulence of infectious laryngotracheitis viruses: comparison of modified-live vaccine viruses and North Carolina field isolates. Avian Diseases, 34, 106-113.

Guy, J. S., Barnes, J. H. \& Smith, L. (1991). Increased virulence of modified-live infectious laryngotracheitis vaccine virus following bird-to-bird passage. Avian Diseases, 35, 348-355.

Helferich, D., Veits, J., Teifke, J. P., Mettenleiter, T. C. \& Fuchs, W. (2007). The UL47 gene of avian infectious laryngotracheitis virus is not essential for in vitro replication but is relevant for virulence in chickens. Journal of General Virology, $88,732-742$. 
Honda, T., Okamura, H., Taneno, A., Yamada, S. \& Takahashi, E. (1994). The role of cell-mediated immunity in chickens inoculated with the cell-associated vaccine of attenuated infectious laryngotracheitis virus. Journal of Veterinary Medical Science, 56, 1051-1055.

Hughes, C. S., Gaskell, R. M., Jones, R. C., Bradbury, J. M. \& Jordan, F. T. W. (1989). Effects of certain stress factors on the re-excretion of infectious laryngotracheitis virus from latently infected carrier birds. Research in Veterinary Science, 46, 274276.

Hughes, C. S., Williams, R. A., Gaskell, R. M., Jordan, F. T. W., Bradbury, J. M., Bennet, M. \& Jones, R. C. (1991). Latency and reactivation of infectious laryngotracheitis vaccine virus. Archives of Virology, 121, 213-218.

Kirkpatrick, N. C., Mahmoudian, A., Colson, C. A., Devlin, J. M. \& Noormohammadi, A. H. (2006). Relationship between mortality, clinical signs and tracheal pathology in infectious laryngotracheitis. Avian Pathology, 35, 449-453.

May, H. G. \& Titsler, R. P. (1925). Tracheolaryngotracheitis in poultry. Journal of the American Veterinary Medical Association, 67, 229-231.

Mebatsion, T., Melson, L. \& Hein, R. (2008). A novel HVT-based recombinant vaccine (Innovax-ILT) to simultaneously control infectious laryngotracheitis and Marek's disease in chickens. In Proceedings of the XXIII World's Poultry Conference. Brisbane, Queensland, Australia.

Mundt, A., Mundt, E. \& García, M. (2010). Generation of a glycoprotein J deletion mutant of infectious laryngotracheitis virus (ILTV) as potential vaccine for DIVA approach. In Proceedings of the 2010 AAAP Annual meeting. Atlanta GA, United States of America. 
Neff, C., Suddler, C. \& Hoop, R. K. (2008). Characterization of western European field isolates and vaccine strains of avian infectious laryngotracheitis virus by restriction fragment length polymorphism and sequence analysis. Avian Diseases, $52,278-283$.

Ojkic, D., Swinton, J., Vallieres, M., Martin, E., Shapiro, J., Sanei, B. \& Binnington, B. (2006). Characterization of field isolates of infectious laryngotracheitis from Ontario. Avian Pathology, 35, 286-292.

Oldoni, I. \& García, M. (2007). Characterization of infectious laryngotracheitis virus isolates from the United States by polymerase chain reaction and restriction fragment length polymorphism of multiple genome regions. Avian Pathology, 36, 167-176.

Oldoni, I., Rodriguez-Avila, A., Riblet, S. \& Garcia, M. (2008). Characterization of infectious laryngotracheitis virus (ILTV) isolates from commercial poultry by polymerase chain reaction and restriction fragment length polymorphism (PCRRFLP). Avian Diseases, 52, 59-36.

Oldoni, I., Rodriguez-Avila, A., Riblet, S., Zavala, G. \& Garcia, M. (2009). Pathogenicity and growth characteristics of selected infectious laryngotracheitis virus strains from the United States. Avian Pathology, 38, 47-53.

Pavlova, S. P., Veits, J., Blohm, U., Maresch, C., Mettenleiter, T. C. \& Fuchs, W. (2010). In vitro and in vivo characterization of glycoprotein C-deleted infectious laryngotracheitis virus. Journal of General Virology, 91, 847.

Purcel, D. A. \& Surman, P. G. (1974). Letter: aerosol administration of the SA-2 vaccine strain of infectious laryngotracheitis virus. Australian Veterinary Journal, $50,419-420$. 
Sun, H.-L., Wang, Y.-F., Tong, G.-Z., Zhang, P.-J., Miao, D.-Y., Zhi, H.-D., Wang, M. \& Wang, M. (2008). Protection of chickens from Newcastle disease and infectious laryngotracheitis with a recombinant fowlpox virus co-expressing the F, HN genes of Newcastle disease virus and $\mathrm{gB}$ gene of infectious laryngotracheitis virus. Avian Diseases, 52, 111-117.

Williams, R. A., Bennet, M., Bradbury, J. M., Gaskell, R. M., Jones, R. C. \& Jordan, F. T. W. (1992). Demonstration of sites of latency of infectious laryngotracheitis virus using the polymerase chain reaction. Journal of General Virology, 73, 24152420. 
Figure 1. Boxplot of the percentage weight gain of male and female chickens after vaccination. Groups marked with the same letter $(A, B, C)$ in each panel did not have significantly different weight gains $(P>0.05)$. Asterisks indicicate outlier values.

Figure 2. Boxplot of the percentage weight gains of male and female chickens after challenge. Values with the same letter $(A, B, C)$ in each panel did not have significantly different weight gains $(P>0.05)$. Asterisks indicate outlier values.

Table 1. Clinical scores, ELISA and $q P C R$ results at 5 and 21 days after vaccination in safety study

Table 2. Clinical sign scores, tracheal histopathology scores and qPCR results at 5 and 6 days after challenge in efficacy study 
Table.1: Strains of Enterobacteriaceae isolated.

\begin{tabular}{|c|c|}
\hline Species & N. strains \\
\hline Buttiauxella agrestis & 2 \\
\hline Citrobacter brackii & 1 \\
\hline Citrobacter freundii & 4 \\
\hline Citrobacter youngae & 3 \\
\hline Enterobacter spp. & 2 \\
\hline Enterobacter aerogenes & 5 \\
\hline Enterobacter amnigenus & 3 \\
\hline Enterobacter cancerogenus & 12 \\
\hline Enterobacter cloacae & 45 \\
\hline Enterobacter sakazakii & 6 \\
\hline Escherichia coli & 53 \\
\hline Hafnia alvei & 2 \\
\hline Klebsiella pneumoniae & 2 \\
\hline Klebsiella pneumoniae subsp. ozaenae & $\mathbf{1}$ \\
\hline Klebsiella pneumoniae subsp. rhinoscleromatis & 2 \\
\hline Klebsiella oxytoca & 4 \\
\hline Kluyvera spp. & 1 \\
\hline Pantoea spp. & 4 \\
\hline Proteus mirabilis & 1 \\
\hline Providencia alcalifaciens/rustigianii & $\mathbf{1}$ \\
\hline Providencia rettgeri & 1 \\
\hline Raoultella terrigena & 1 \\
\hline Salmonella bongori 48:z35:- & 2 \\
\hline Serratia liquefaciens & 2 \\
\hline Serratia marcescens & 5 \\
\hline Serratia odorifera & 1 \\
\hline Yersinia enterocolitica & 8 \\
\hline Non fermenting species & 9 \\
\hline Total & 183 \\
\hline
\end{tabular}

